\title{
TECHNICAL DEVELOPMENT PATH FOR FOIL GAS BEARINGS
}

\author{
Dr. Christopher DellaCorte \\ NASA, Glenn Research Center \\ Cleveland, Ohio
}

\begin{abstract}
Foil gas bearings are in widespread commercial use in air cycle machines, turbocompressors and microturbine generators and are emerging in more challenging applications such as turbochargers, auxiliary power units and propulsion gas turbines. Though not well known, foil bearing technology is well over fifty years old. Recent technological developments indicate that their full potential has yet to be realized. This paper investigates the key technological developments that have characterized foil bearing advances. It is expected that a better understanding of foil gas bearing development path will aid in future development and progress towards more advanced applications.
\end{abstract}

\section{INTRODUCTION}

Foil gas bearing technology evolved from rigid gas bearings as a means to overcome physical limitations that resulted from operating a bearing using low viscosity fluids and modest self generated hydrodynamic fluid film pressures, namely the inability to tolerate misalignment and distortion and a lack of adequate damping and stability [1]. By incorporating thin sheet metal foils in place a rigid bearing surface both compliance and coulomb friction damping capabilities were added to the bearing. The flexibility of the geometry as influenced directly by the fluid film pressure gives rise to improved performance and more complexity in terms of bearing modeling [2]. These characteristics were recognized early in the development history of foil bearings $[3,4]$. Despite challenges facing performance prediction, foil bearings followed a fairly routine experimentally driven development path. Current efforts to apply modern analysis techniques to predict performance and develop design tools have been hindered by a scarcity of publically available bearing dimensional data [5]. In this paper, the technological development path is examined to better understand key technological breakthroughs in bearing design, performance and understanding that have led to today's third generation, advanced technology bearings. It is expected that an enhanced understand of the foil bearing development path will help guide further developments and applications.

\section{EARLY DEVELOPMENT}

While searching for a convenient means to study fluid film phenomena in oil lubricated sleeve bearings, Blok and Von Rossum built, observed and reported a new type of bearing in which the fluid pressure deflected a flexible bearing surface made from a foil of clear plastic film [3]. They called this bearing a foil bearing and pointed out that such a bearing enjoys a thicker fluid film with potentially lower friction than its rigid bearing counterpart. This is a key technological feature of a foil bearing; namely that the hydrodynamic fluid film pressure creates the clearance by deflecting the bearing away from the shaft surface. Thus a bearing designer is not necessarily forced to pre-select a bearing clearance. This new design freedom helped to overcome a primary limitation in gas bearings, that is tolerance to shaft misalignment, distortion and centrifugal growth which had plagued rigid bearings in many high speed and high temperature applications.

Several years later, in 1957, Cameron and Patel in trying to measure oil film temperature distribution in a working bearing, replaced the clear plastic film with sheet metal, studded with thermocouples, in their foil bearing [4]. These experiments showed that a foil bearing could be made with engineering materials, like metal, and that such a foil bearing offered a more uniform film thickness that would turn out to be vital to foil bearings utilizing thin gas films to achieve surface separation. Interestingly, there is little or no written evidence that suggests these researchers studying oil-lubricated foil bearing realized the importance of their findings on gas bearing technology.

Working at IBM's New York research lab on gas bearing spindles and on high-speed tape recorders, however, H.K. Baumeister appears to have identified that a lubricating film of air was formed between the flexible tape and the read write head. In internal IBM documents, later released, he refers to this phenomenon as a type of foil bearing. Study of this lubricating film was named "the foil bearing problem $[6,7]$. Though Baumeister is amongst the very first to make the connection between gas hydrodynamics and the foil bearing no serious attempts were made to turn this nuisance to the recording industry into a practical bearing device until the concept was studied and alluded to in the classic 1962 book by W.R. Gross [8]. Gross shortly thereafter moved from IBM's California labs to AMPEX and managed a government funded project to study and build a practical foil air bearing to help satisfy the need for high speed shaft support encountered in several space and other advanced machines under development $[9,10]$. Thus invention of the foil gas bearing required a decade of work by several independent investigators. Early government support with widespread dissemination of the results yielded the primitive tension dominated bearings as 
depicted in figure 1. None of these primitive bearings found commercial applications but played a vital role in laying the foundation for improved bearings that followed.

\section{FIRST GENERATION BEARINGS}

A 1967 gas bearing symposium, held in London, highlighted the concept of using several leafs of foil cantilevered to form a foil bearing [11]. This concept was turned into the first practical foil bearing developed by industry for air cycle machines used for cabin pressurization [12]. With this approach, the limited hydrodynamic gas film pressure was not utilized to overcome foil tension forces found in earlier tape type bearings. Other bending dominated designs based upon small corrugations in underlying bump foils soon followed [13]. These first generation foil bearings are depicted in figure 2.

\section{SECOND GENERATION BEARINGS}

Following the commercialization of first generation bending dominated bump and leaf foil bearings in ACM's, several new designs were developed in which the elastic bearing substructure was tailored to accommodate hydrodynamic phenomena such as edge leakage and environmental conditions such as misalignment and gravitational load biases. These second generation foil bearings are shown in figure $3[14,15]$. Second generation bearings showed a load capacity double that of first generation designs and made possible the development of more demanding applications such as cryogenic turboexpanders.

\section{THIRD GENERATION BEARINGS}

In the late 1980's and early 1990's Heshmat pioneered the development of a third generation of foil bearings in which the elastic foundation stiffness was tailored in more than one direction [16]. Employing multiple bump spring layers and circumferentially slit support foils, these Generation III bearings enabled the tuning of the bearing structural stiffness and damping properties. Gen III bearings display improved dynamic properties and load capacities nearly double Gen II designs. Since that time, others have developed alternative approaches to achieve similar structural design freedoms utilizing now public domain multiple bump foil concepts, webbed spring tabs and multiple cantilevered spring layers. A recent notable design by Kang and Saville includes the first ever self-preloaded bearing foils in which the top or inner foil springs against the bump foil layers negating the need to preload the bearing against the shaft [17]. This design reduces wear and starting torque and appears simple to manufacture.

In all, these new bearings have enabled foil bearing commercialization into ever more complex and demanding machines such as turbochargers, microturbines and large blowers. Selected demonstrations in propulsion gas turbines and space power applications are being explored [18-20]. Continuing bearing development and new application experience indicates that more Oil-Free foil bearing supported machines are likely to enter service in the coming years and that each of these benefits from the breakthrough work of many pioneering contributors.

\section{REFERENCES}

[1] Licht, L., and Branger, M., 1973, "Design, Fabrication, and Performance of Foil Journal Bearings for the Brayton Rotating Unit," NASA Contractor Report CR-2243, July 1973.

[2] Ma, J.T.S., 1965, "An Investigation of Self-Acting Foil Bearings," ASME Journal of basic Engineering, pages 837-846, December 1965.

[3] Blok, H., and Van Rossum, J.J., 1953, "The Foil BearingA New Departure in Hydrodynamic Lubrication," Lubrication Engineering, volume 9, pages 316-320, December 1953.

[4] Patel, B.J., and Cameron, A., 1957, "The Foil Bearing," Proceedings of the IME, London Conference on lubrication and Wear, Paper Number 73, 1957.

[5] DellaCorte, C., Radil, K.C., Bruckner, R.J., and Howard, S.A., 2007, "Design, Fabrication amd Performance of Open Source Generation I and II Compliant Hydrodynamic Foil Gas Bearings," NASA TM 2007-214691, April 2007.

[6] Gross, W.A., 1958, "Film Lubrication-V. Infinitely Long Incompressible Lubricating Films of Various Shapes," IBM Research Report RJ 117-5, pages 69-70. October 1958.

[7] Koh, R.C., and Langlois, W.E., 1960, "Investigation of the Foil Bearing Problem," IBM Research Report RJ 187, October 1960.

[8] Gross, W.A., 1962, Gas Film Lubrication, John Wiley and Sons, New York, pages 138-114, 1962.

[9] Wildman, M., and Wright, A., 1963, "The Effect of External Pressurization on Self-Acting Foil Bearings," AMPEX Corporation Research and Engineering Publication RR63-6, work performed under Office of Naval Research NONR-3815(00), October 1963.

[10] Licht, L., 1971, "Studies of Foil Journal-Bearings for Brayton Cycle Turbomachinery," final report for work performed under NASA Contract NAS3-13482, NASA CR 72864, February 1971.

[11] Grassam, N.S., 1967, "proceedings of the Third Gas Bearing Symposium-Contributions and Discussions," page B99, University of Southamptom, July 1967.

[12] Barnett, M.A., and Silver, A., 1970, "Application of Air Bearings to High Speed Turbomachinery," SAE Paper 700720 .

[13] Ruscitto, D., McCormick, J., and Gray, S., 1978, "Hydrodynamic Air Lubricated Compliant Surface Bearing for an Automotive Gas Turbine Engine: I-Journal Bearing Performance," NASA CR-135368.

[14] Suriano, F.J., 1981, "Gas Foil Bearing Development Program," US Air Force Report Number AFWAL-TR-812095.

[15] Gray, S., and Bhushan, B., 1981, "Support Element for Compliant Hydrodynamic Journal Bearings," U.S. Patent Number 4,274,683.

[16] Heshmat, H., 1999, "High Load Capacity Compliant Foil Hydrodynamic Journal Bearing," US Patent Number $5,902,049$. 
[17] Kang, D.H., and Saville, M., 2005, "Hydrodynamic Journal Bearing System," US Patent Number 6,964,522.

[18] Klass, R.M, and DellaCorte, C., 2006, "Quest for Oil-Free Gas Turbine Eninges,” SAE paper 2006-01-3055, November 2006.

[19] Howard, S.A., and DellaCorte, C., 2006, "Gas Foil Bearings for Space Propulsion Nuclear Electric power Generation,"NASA TM-2006-214115.

[20]DellaCorte, C., and Bruckner, R.J., "Oil-Free Rotor Support Technologies for an Optimized Helicopter Propulsion System," NASA TM-2007-214845 and ISABE paper number 2007-1145.

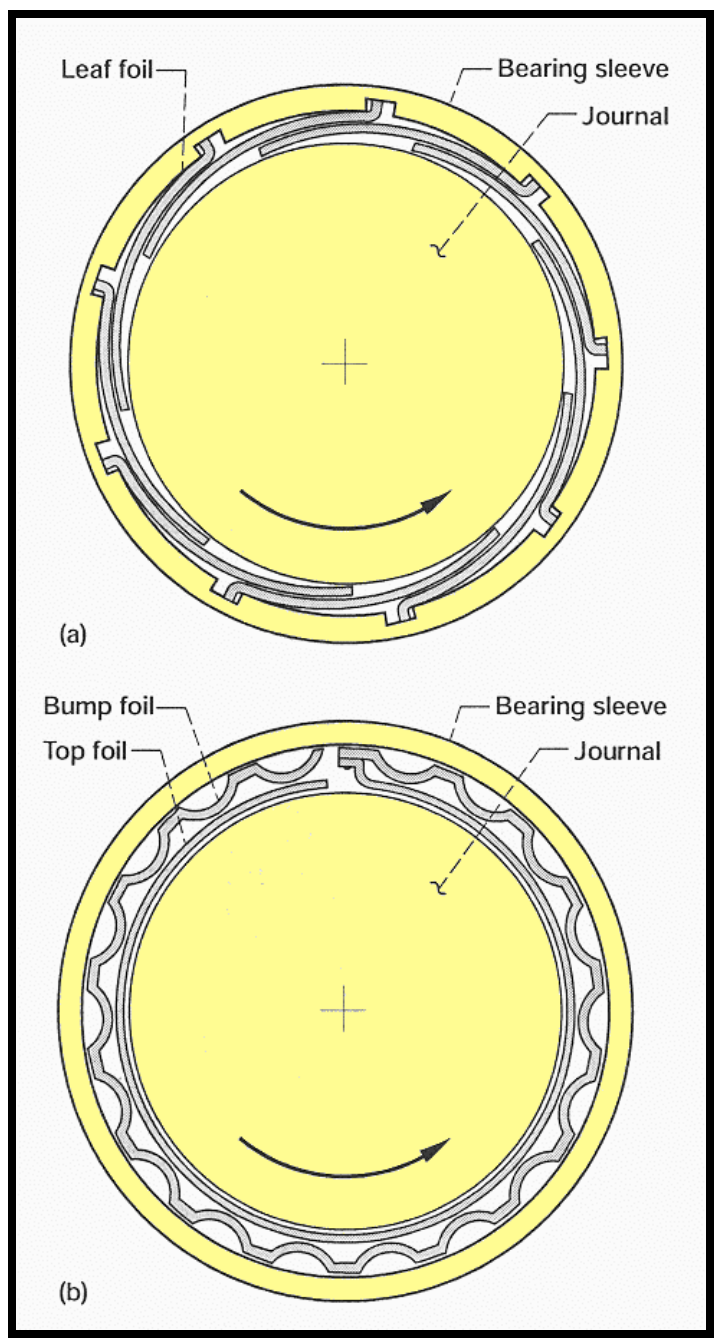

Figure 1-(a) Generation I leaf type and (b) Generation I bump type foil bearing 


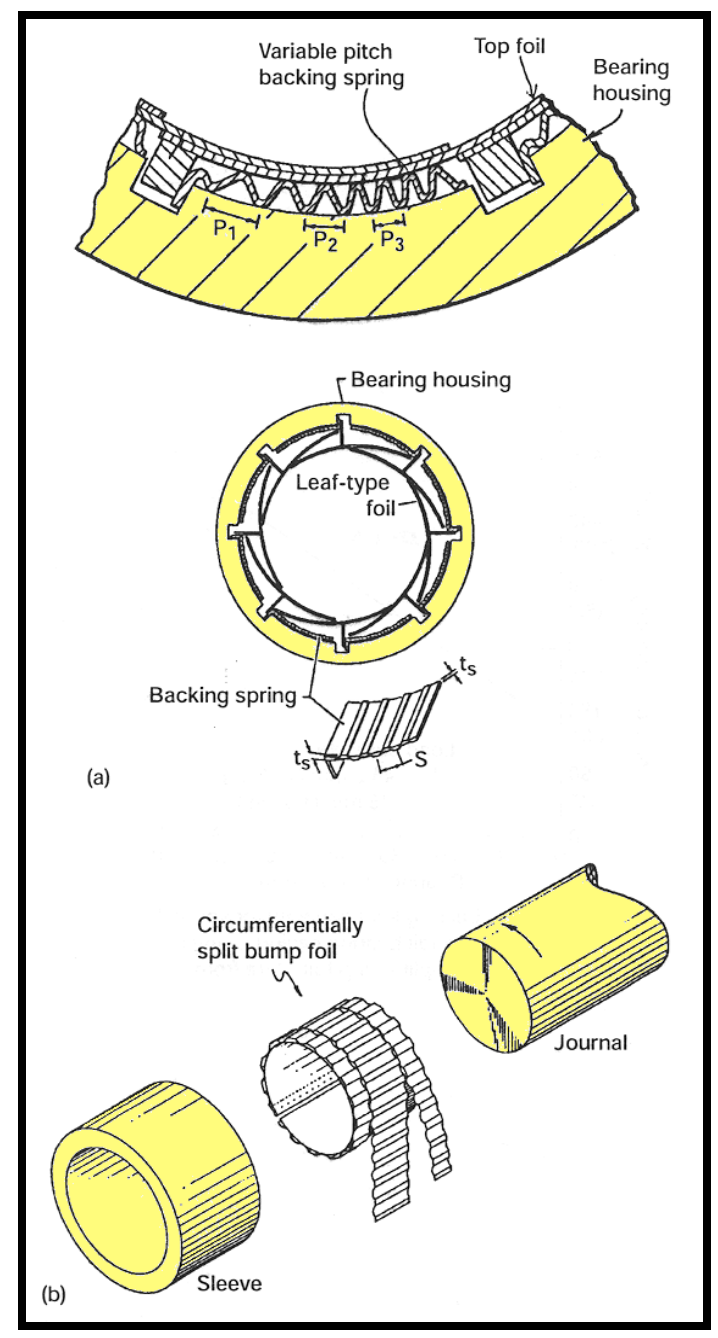

Figure 2-Generation II foil bearings with circumferential (a) and axial (b) tailoring of the supporting bump foil structure.

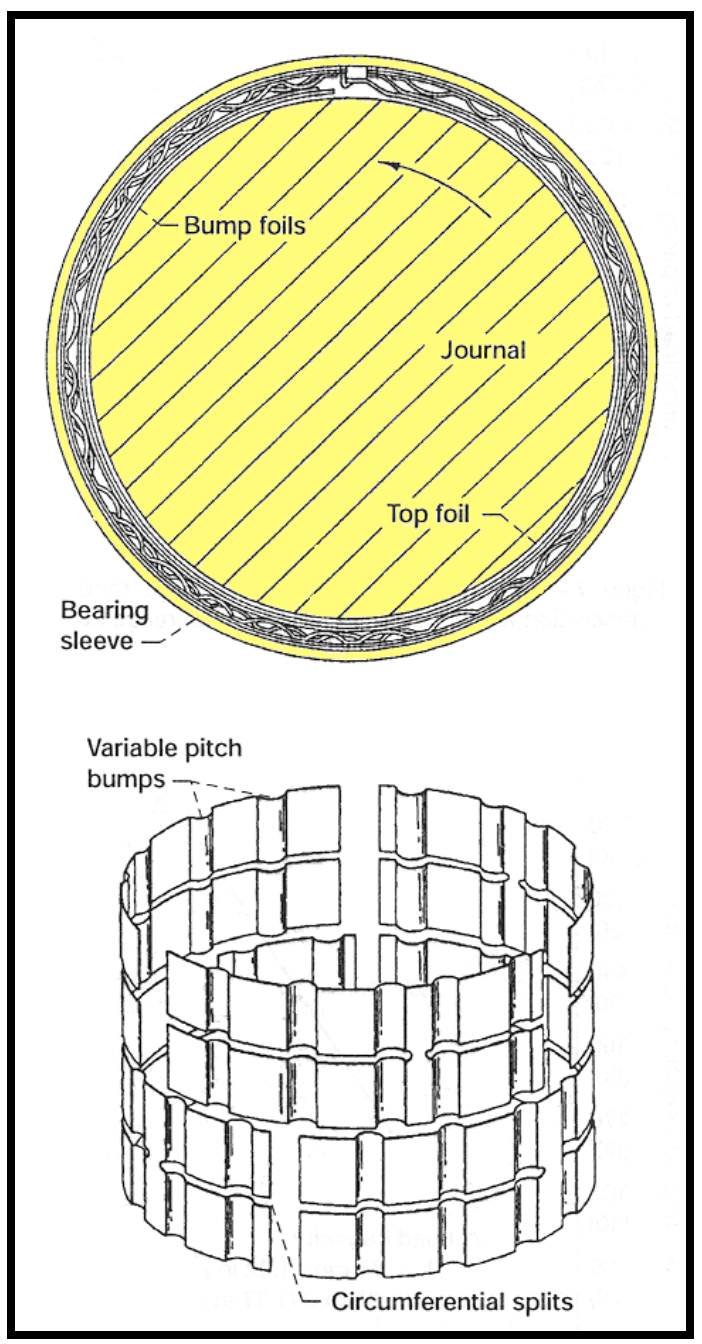

Figure 3-Generation III bump foil bearing showing a combination of axial and circumferential structural stiffness tailoring. 